\title{
Reflux Esophagitis is Associated with Higher Risks of Acute Stroke and Transient Ischemic Attacks in Patients Hospitalized with Atrial Fibrillation: A Nationwide Inpatient Sample Analysis
}

\author{
Yi Jiang, MD ${ }^{1,}$; Konstantinos Damiris, DO $^{1}$; Giselle A. Suero-Abreu, MD, PhD ${ }^{1}$; Sushil Ahlawat, MD $^{2}$ \\ ${ }^{1}$ Department of Medicine, Rutgers University New Jersey Medical School, Newark, NJ, USA \\ ${ }^{2}$ Division of Gastroenterology and Hepatology, Rutgers University New Jersey Medical School, Newark, NJ, USA \\ ${ }^{\text {a }}$ Correspondence: \\ Department of Medicine, Rutgers New Jersey Medical School \\ 150 Bergen Street, UH I-248, Newark, NJ 07101, USA \\ yi.jiang@rutgers.edu
}

\section{$\underline{\text { Abstract }}$}

Objective: Reflux esophagitis (RE) is a subset of gastroesophageal reflux disease (GERD) with endoscopic evidence of esophageal inflammation, which has been linked to an increased incidence of atrial fibrillation (AF). However, data on the effect of RE on patient outcomes is limited. We sought to examine the potential association of RE with outcomes of patients with AF in a nationwide study.

Methods: The National Inpatient Sample (NIS) database was queried to identify hospitalized adult patients with AF and RE between 2010 and 2014. Primary outcomes included inpatient mortality, length of stay (LOS), and total hospital charges. AF related complications such as acute stroke, transient ischemic attack (TIA) and acute heart failure were assessed as secondary outcomes. Propensity score matching and multivariate regression analysis were used.

Results: 667,520 patients were admitted for primary diagnosis of AF out of which 5,396 had a secondary diagnosis of RE. In the AF with RE cohort, the average age was 73.6 years, $41.5 \%$ were male, and $79.9 \%$ were Caucasian. There was a greater prevalence of concomitant dyslipidemia, chronic liver disease and chronic pulmonary disease $(\mathrm{p}<0.01)$ when compared to the AF without RE cohort. Patients with AF and RE also had higher incidence of acute strokes and TIAs ( $\mathrm{p}<0.05)$, longer LOS $(\mathrm{p}<0.001)$, and higher hospital charges $(\mathrm{p}<0.05)$ with no difference in acute heart failure $(\mathrm{p}=0.08)$, hospital mortality $(\mathrm{p}=0.12)$, or $\mathrm{CHA}_{2} \mathrm{DS}_{2}$-VAS score $(\mathrm{p}=0.67)$.

Conclusion: In hospitalized patients with AF, RE was associated with a higher rate of acute stroke and TIA, longer LOS, and greater hospital charges.

Keywords: Reflux esophagitis, Gastroesophageal reflux disease, Atrial Fibrillation, Stroke, Transient ischemic attack, Inflammation, Epidemiology, Population-based studies.

\section{Introduction}

Gastroesophageal reflux disease (GERD) is a pathologic condition that develops from the reflux of stomach contents, which causes a variety of troublesome clinical symptoms with or without complications [1]. With an estimated prevalence of 8-33\% worldwide, and 18-28\% in the United States (US) alone; it carries a cost of more than 9-10 billion dollars per year in the US [2-4]. Notably, GERD is the most common indication for esophagogastroduodenoscopy in the US [5]. Reflux esophagitis (RE) describes a subset of patients with GERD who have endoscopic evidence of esophageal inflammation.

Atrial fibrillation (AF) is the most common cardiac rhythm disorder [6], affecting 2.3 million individuals in the US [7]. Its effects are profound, as it is associated with a 3-5 fold increase for stroke [8] and a two fold increase of all-cause mortality [9]. CHA2DS2-VASc risk stratification score has been used widely for estimation of stroke risk for nonvalvular AF in adults [10] and can assist with the decision of initiating anticoagulation therapy [11].
The coexistence of GERD/RE and AF, is frequently encountered in the clinical setting and increases the complexity of patients' diagnosis and treatment. Pathogenetically, AF has been shown to be associated with inflammatory disorders and abnormalities of left atrium geometry [12]. Based on the close proximity of the esophagus and the left atrium, the interaction between GERD/RE and AF has been proposed. GERD was reported to be associated with an increased risk of AF [13-15] in some studies. However, the results have been controversial due to limited sample sizes or underpowered study design. Moreover, the impact of GERD on outcomes of AF related hospitalization has been underexplored.

Bunch et al [16] suggested that the presence of esophagitis instead of GERD symptoms alone plays a pivotal role in triggering and promoting AF. Therefore, we aimed to examine the influence of RE, instead of the clinical diagnosis of GERD, on the outcomes in adult patients hospitalized for AF. 


\section{Materials and Methods}

\subsection{Data Source and Study Population}

In this study the National Inpatient Sample (NIS) database [17] was utilized to assess patient demographics, hospital characteristics and inpatient admission outcomes of $20 \%$ of all in-patient hospitalizations within the United States. Patient data was obtained using the International Classification of Diseases-Ninth Edition Revision, Clinical Modification (ICD-9 CM) codes allowing for identification of diagnoses and procedures associated with patients' hospitalization. This retrospective cohort study examined adult patients, ages 18-90 years, admitted between 2010 and 2014. Primary diagnosis (first or second admission diagnosis) of AF (ICD-9 code 427.31) and secondary diagnosis of RE (ICD-9 code 530.11) was utilized. Patients with AF and co-existing RE were compared to those without RE. Collected data included patient demographics, comorbidities, post-hospitalization disposition, and other various outcomes (Tables 1-3). Patient medical comorbidities were categorized using the approved Elixhauser Comorbidity Index (ECI) score [18], which uses 29 common medical conditions and proceeds to calculate a weighted compiled score used to predict hospital resource use and mortality amongst hospitalized patients. Primary outcomes included inpatient mortality, length of stay (LOS), and accrued total hospital charges. Secondary outcomes included AF with and without RE leading to complications including acute stroke, TIA and acute heart failure.

\subsection{Statistical Analysis}

All statistical analyses were performed using SAS Survey Procedures (SAS 9.4, SAS Institute Inc, Cary, NC, USA). Confounding variables included patient age, sex, race, primary insurance payer, hospital type, hospital bed size, hospital region and hospital teaching status. These variables were controlled using propensity score matching $[19,20]$ with use of multivariate logistic regression model. With use of 8-to-1-digit match, each admission of AF with RE was matched with one admission from AF without RE. National estimates were calculated after accounting for the sample design elements (clusters, strata, and trend weights) provided by the NIS. All continuous variables are reported as weighted means \pm standard errors (SE). All categorical variables are displayed as weighted numbers $(\mathrm{N})$ and percentages $(\%)$. Paired t-tests were used for the comparison of normally distributed continuous variables, while Wilcoxon Rank-Sum Test was used for non-normally distributed continuous variables. Categorical variables were analyzed using the Rao-Scott modified chi-square test. Multivariate linear regression was used to estimate the average change in LOS and total hospital charges after adjusting for patient demographics (age, sex, race), hospital bed size, insurance type, median household income, ECI score, CHA2DS2-VASC Score, dyslipidemia, chronic liver disease and chronic pulmonary disease. Multivariate logistic regression calculated the odds ratio of outcomes after adjusting for the prior mentioned confounding variables.

\subsection{Ethical information}

The NIS database is publicly available and includes only de-identified patient demographics. This study was a retrospective study; therefore, no patients were actively involved, making Institutional Review Board approval non-applicable.

\section{Results}

\subsection{Patient Demographics and Baseline Characteristics}

A total of 667,520 patients were admitted for primary diagnosis of AF, of which 5,396 patients had documented diagnosis of coexisting RE. These patients were matched with 5,396 AF patients without RE. The $\mathrm{AF}$ with $\mathrm{RE}$ cohort in this study was predominantly a geriatric Caucasian population with an average age of 73.6, and an average ECI score of 3.3 . $58.5 \%$ of patients were female. $76.6 \%$ patients were insured by Medicare, and $67.9 \%$ were discharged routinely (Table 1). Compared to AF patients without RE, there were no differences in the demographic variables examined. The AF with RE cohort was associated with significant comorbid conditions. About $90 \%$ patients in this cohort had a $\mathrm{CHA}_{2} \mathrm{DS}_{2}$-VASc Score $\geq 2,71.1 \%$ had coexisting hypertension, $26.5 \%$ had diabetes, and half of the patients had dyslipidemia. AF with $\mathrm{RE}$ patients had a significantly greater prevalence of concomitant dyslipidemia $(\mathrm{p}=0.0018)$, chronic liver disease $(\mathrm{p}=0.0067)$ and chronic pulmonary disease $(\mathrm{p}=0.0001)$ compared to AF without RE (Table 2). No statistically significant differences in ECI score, $\mathrm{CHA}_{2} \mathrm{DS}_{2}$-VASc Score or AF-related procedure rates were found between $\mathrm{AF}$ with $\mathrm{RE}$ vs. AF without RE group.

\subsection{Outcomes and Regression Analysis of AF patients with and without RE}

When compared to AF without RE group, AF with RE patients had a higher incidence of acute strokes and TIAs [0.46\% vs. $0.19 \%$, adjusted odds ratio $(\mathrm{aOR})=2.34,95 \%$ confidence interval $(\mathrm{CI}) 1.1-4.99, \mathrm{p}<$ 0.05 ), longer LOS (4.05 days vs 3.48 days, adjusted coefficient 0.54 , 95\% CI 0.27-0.82, $\mathrm{p}=0.0001)$, and higher hospital charges $(\$ 36,095$ vs. $\$ 32,114$, adjusted coefficient $3,890,95 \%$ CI $483-7,297, \mathrm{p}<0.05$ ). There were no differences in either acute heart failure or hospital mortality (Table 3).

\section{Discussion}

This nationwide study examined the impact of RE on the outcomes of patients hospitalized for AF. Our study population was predominantly geriatric Caucasian patients who had high comorbidity burden and high risk for stroke based on the $\mathrm{CHA}_{2} \mathrm{DS}_{2}$-VASc score. We suspect that elderly patients who have a high comorbidity burden may be indicated for endoscopy more often secondary to alarm symptoms and complicated GERD [21]. They may also be indicated for hospitalization to treat active AF-related comorbidities more often than the general population. This study demonstrated that $\mathrm{AF}$ with $\mathrm{RE}$ was independently associated with an increased risk of inpatient acute stroke and TIAs, longer LOS, and higher hospitalization costs compared to AF without RE.

Several epidemiological studies have suggested that GERD, particularly esophagitis, is associated with increased risk of AF onset and maintenance $[13,14]$. Some studies further demonstrated that protonpump inhibitors help ameliorate AF symptoms and facilitate conversion from AF to sinus rhythm in a subset of patients with GERD [22,23], which indirectly suggests the relationship between GERD and AF. The potential GERD-associated arrhythmogenic mechanisms have been proposed based on three main factors from animal models and clinical findings [14,24]: esophageal inflammation, autonomic nerve activation, and mechanical irritation from the esophagus to the nearby left atrium. 
Despite both AF and RE being common diseases with significant causal relationship, little is known regarding how RE affects the outcomes of AF.

RE potentially contributes to an increased stroke risk in AF by both the localized and systemic inflammation present with the disease. Importantly, it has been suggested in both human and animal models that RE develops as a cytokine-mediated inflammatory injury [25] and not as a caustic chemical injury, as traditionally theorized. Souza et al [26] developed a RE rat model after esophagoduodenostomy and found the inflammation did not start in the mucosa, but deep in the epithelium by histological study. Later it was found that stopping proton-pump inhibitors in patients with severe RE was associated with esophageal inflammation without loss of surface cells [27,28]. It was demonstrated that esophageal epithelial cells secreted interleukin (IL)-8, IL-1 $\beta$, and other potent proinflammatory cytokines when exposed to acidic bile salts [26]. Additionally, it was reported that inflammatory pathways are not only involved in the initiation and maintenance of $\mathrm{AF}$, but also contribute to both electrical and structural atrial remodeling and thrombogenesis in patients with AF [29]. Many systemic inflammatory diseases are accompanied by adverse atrial remodeling and an enhanced risk of stroke [30,31]. Systemic inflammatory disorders can cause inflammatory injury to the coronary microcirculation, leading the microvascular dysfunction as well as myocardial fibrosis [12]. The extension of the systemic inflammatory process to the atrial wall has been evidenced by significant left atrial abnormalities on cardiac images [32]. Moreover, states of inflammation cause deranged adipogenesis of epicardium, which is connected with the myocardium through an unobstructed microcirculation. Dysfunctional epicardial adipose tissue expands its mass and secretes proinflammatory adipocytokines, which are further linked to the anatomical and pathophysiological substrates for $\mathrm{AF}[33,34]$ and its severity [35]. In conjunction, RE associated inflammatory injury can potentially lead to microvascular and microcirculation changes in the cardiovascular system from cytokine release, leading to dysregulated electrical activity. Secondarily, the close proximity of the esophagus and the left atrium can lead to extension of inflammation to the atrial wall and epicardium, further influencing the aforementioned left atrial geometric change and epicardial adipose tissue expansion. These heart structural abnormalities, together with reinforced inflammatory status, subsequently trigger the pathogenesis of thromboembolic events.

Reactive oxygen species (ROS) and oxidant stress [36] are also related to $\mathrm{RE}$ pathogenesis and affect the risk of $\mathrm{AF}$ and related adverse events. Feagins et al [37] has reported that upon exposure to acid and bile salts, cultured esophageal squamous cells increase ROS production. The ROS, together with hypoxia from tissue inflammation, induced the production of hypoxia-inducible factors (HIF)-2 $\alpha$, which mediate the expression of pro-inflammatory molecules [38] and function as initiators of the cytokine-mediated inflammation. ROS and oxidant stress have been recognized as important contributors to atrial remodeling in AF [39-41]. Studies have shown that several ion channels and their regulators expressed in the atria are sensitive to redox state under oxidant stress [42]. A decreased atrial calcium current and a diminished contractile response to adrenergic agonists have been observed during experimental inhibition of glutathione synthesis [43]. It was proposed that pathologic processes that increase oxidant production via any of the several pathways might have a similar electrical and contractile phenotype that is associated with AF [39]. Hence, ROS production in RE exacerbates both inflammatory and oxidative pathways, which have been implicated in the AF-related atrial geometry abnormalities and further thromboembolic events.
Interestingly, despite the statistically significant higher rate of inpatient stroke and TIAs in the AF with RE group, there was no difference in overall $\mathrm{CHA}_{2} \mathrm{DS}_{2}$-VASc score or any of its components. RE increased acute stroke and TIA risk in a way that exceeds that predicted by the presence of traditional cardiovascular risk factors. Similarly, it is reported that the rate of stroke in patients with known $\mathrm{AF}$ and systemic autoimmune diseases is greater than can be explained by the $\mathrm{CHA}_{2} \mathrm{DS}_{2}$ VASc score $[44,45]$. Notably, clinical studies have reported that the risk of $\mathrm{AF}$ and related thromboembolic events are particularly apparent in clinically severe inflammatory disease [31] Anatomically, pericardial fat volume expansion, which is linked to AF onset and adverse events, has also been proved to be proportional to the inflammatory disease clinical severity and the intensity of inflammation [12]. Collectively, thromboembolic risk of AF may be positively correlated with the severity and intensity of local or systemic inflammation. The $\mathrm{CHA}_{2} \mathrm{DS}_{2}$-VASc score does not incorporate measures of inflammation or direct assessments of the atrial myopathy or abnormal geometry, therefore the predictive accuracy in severe inflammatory disease is compromised [12]. Indeed, some have proposed that the CHA2DS2VASc score be modified in patients who have a systemic inflammatory disorder [46].

This study showed higher rates of chronic pulmonary and liver diseases in hospitalized AF patients with RE compared with those without RE. These patients with RE may be symptomatic from diseases of other systems and may seek medical attention more often than those without reflux symptoms. Repeat medical attention may result in identification of disease from other systems like chronic pulmonary or liver diseases, as demonstrated in this study. More investigation will be needed to uncover the underlying correlation between RE and pulmonary or liver disease in $\mathrm{AF}$ patients.

Our study has several strengths. To the best of our knowledge, this is a leading nationwide study to address the impact of RE on outcomes for hospitalized AF patients. Our study went beyond the correlation studies of these two diseases and focused on the clinical outcomes. The results suggested that additional information about severity and intensity of inflammation may help improve the predictive accuracy of thromboembolic risk score in AF patients with significant inflammatory disease. Also, we used propensity score matching and multivariate analysis to isolate the effect of RE after adjusting for a full list of possible confounders including ECI score and $\mathrm{CHA}_{2} \mathrm{DS}_{2}$-VASc score. On the other hand, limitations of this study are worth noting. Because of inherent limitations from NIS, all diagnoses included depend on the accuracy of ICD-9 codes and medical documentation. The supportive clinical symptoms, signs, diagnostic images, labs, and medication administration were shared between physicians and coding professionals, but are not included in the NIS database. The quality control is regularly performed by the third parties: The Agency for Healthcare Research and Quality (AHRQ) and Healthcare Cost and Utilization Project (HCUP).

In conclusion, this nationwide study examined the impact of RE on the outcomes of patients hospitalized for AF. The results suggested RE independently increased stroke and TIA risk in hospitalized patients with AF. This finding may guide clinical decision making on anticoagulation and/or other treatment modalities targeted at alleviating cardiac arrhythmia. Patients with significant inflammatory diseases with or without left atrium geometry changes may benefit from anticoagulation for stroke risk reduction even with low $\mathrm{CHA}_{2} \mathrm{DS}_{2}$ VASc scores. In the future, prospective studies with long term follow up, focusing on assessing the effect of inflammation severity and 
intensity on thromboembolic risk in AF patients with GERD related diseases, may help better risk stratification. Understanding the complex pathophysiological process of RE-associated AF might help to identify specific anti-reflux or anti-inflammatory strategies for the treatment of $\mathrm{AF}$ and the prevention of AF-related adverse events [47].

\section{Author Contributions and Notes}

Y.J and K.D. designed research, Y.J and K.D. performed research, Y.J analyzed data; and Y.J and K.D. and G.A.S.A. wrote the paper. Y.J and K.D. and G.A.S.A and S.A critical review of paper.

The authors declare no conflict of interest.

\section{Acknowledgments}

We thank Luka Petrovic, MD, Cardiology Fellow at Mount Sinai Morningside Health Care System for his professional suggestions from Cardiology perspectives.

\section{References}

1. Vakil N, van Zanten SV, Kahrilas P, Dent J, Jones R, Global Consensus G. The Montreal definition and classification of gastroesophageal reflux disease: a global evidence-based consensus. Am J Gastroenterol 2006; 101 (8): 1900-1920; quiz 1943.

2. Shaheen NJ, Hansen RA, Morgan DR, Gangarosa LM, Ringel Y, Thiny MT, et al. The burden of gastrointestinal and liver diseases, 2006. Am J Gastroenterol 2006; 101 (9):2128-2138

3. El-Serag HB, Sweet S, Winchester CC, Dent J. Update on the epidemiology of gastro-oesophageal reflux disease: a systematic review. Gut 2014; 63 (6):871-880.

4. Gyawali CP, Kahrilas PJ, Savarino E, Zerbib F, Mion F, Smout A, et al. Modern diagnosis of GERD: the Lyon Consensus. Gut 2018; 67 (7):13511362.

5. Peery AF, Dellon ES, Lund J, Crockett SD, McGowan CE, Bulsiewicz WJ, et al. Burden of gastrointestinal disease in the United States: 2012 update. Gastroenterology 2012; 143 (5):1179-1187 e1173.

6. Lip GY, Fauchier L, Freedman SB, Van Gelder I, Natale A, Gianni C, et al. Atrial fibrillation. Nat Rev Dis Primers 2016; 2:16016.

7. Zimetbaum P. Atrial Fibrillation. Ann Intern Med 2017; 166 (5):ITC33ITC48.

8. Kamel H, Okin PM, Elkind MS, Iadecola C. Atrial Fibrillation and Mechanisms of Stroke: Time for a New Model. Stroke 2016; 47 (3):895900.

9. Benjamin EJ, Wolf PA, D'Agostino RB, Silbershatz H, Kannel WB, Levy D. Impact of atrial fibrillation on the risk of death: the Framingham Heart Study. Circulation 1998; 98 (10):946-952.

10. Friberg L, Rosenqvist M, Lip GY. Evaluation of risk stratification schemes for ischaemic stroke and bleeding in 182678 patients with atrial fibrillation: the Swedish Atrial Fibrillation cohort study. Eur Heart J 2012; 33 (12):1500-1510.

11. January CT, Wann LS, Alpert JS, Calkins H, Cigarroa JE, Cleveland JC, Jr., et al. $2014 \mathrm{AHA} / \mathrm{ACC} / \mathrm{HRS}$ guideline for the management of patients with atrial fibrillation: a report of the American College of Cardiology/American Heart Association Task Force on Practice Guidelines and the Heart Rhythm Society. J Am Coll Cardiol 2014; 64 (21):e1-76.

12. Packer M. Characterization, Pathogenesis, and Clinical Implications of Inflammation-Related Atrial Myopathy as an Important Cause of Atrial Fibrillation. J Am Heart Assoc 2020; 9 (7):e015343.

13. Kunz JS, Hemann B, Edwin Atwood J, Jackson J, Wu T, Hamm C. Is there a link between gastroesophageal reflux disease and atrial fibrillation? Clin Cardiol 2009; 32 (10):584-587.
14. Linz D, Hohl M, Vollmar J, Ukena C, Mahfoud F, Bohm M. Atrial fibrillation and gastroesophageal reflux disease: the cardiogastric interaction. Europace 2017; 19 (1):16-20.

15. Huang CC, Chan WL, Luo JC, Chen YC, Chen TJ, Chung CM, et al. Gastroesophageal reflux disease and atrial fibrillation: a nationwide population-based study. PLoS One 2012; 7 (10):e47575.

16. Bunch TJ, Packer DL, Jahangir A, Locke GR, Talley NJ, Gersh BJ, et al. Long-term risk of atrial fibrillation with symptomatic gastroesophageal reflux disease and esophagitis. Am J Cardiol 2008; 102 (9):1207-1211.

17. Agency for Healthcare Research and Quality R, MD. HCUP NIS Database Documentation. Healthcare Cost and Utilization Project (HCUP). wwwhcup-usahrqgov/db/nation/nis/nisdbdocumentationjsp 2019.

18. Moore BJ, White S, Washington R, Coenen N, Elixhauser A. Identifying Increased Risk of Readmission and In-hospital Mortality Using Hospital Administrative Data: The AHRQ Elixhauser Comorbidity Index. Med Care 2017; 55 (7):698-705.

19. Haukoos JS, Lewis RJ. The Propensity Score. JAMA 2015; 314 (15):16371638.

20. Dugoff EH, Schuler M, Stuart EA. Generalizing observational study results: applying propensity score methods to complex surveys. Health Serv Res 2014; 49 (1):284-303.

21. Committee ASoP, Muthusamy VR, Lightdale JR, Acosta RD, Chandrasekhara V, Chathadi KV, et al. The role of endoscopy in the management of GERD. Gastrointest Endosc 2015; 81 (6):1305-1310.

22. Weigl M, Gschwantler M, Gatterer E, Finsterer J, Stollberger C. Reflux esophagitis in the pathogenesis of paroxysmal atrial fibrillation: results of a pilot study. South Med J 2003; 96 (11):1128-1132.

23. Cuomo R, De Giorgi F, Adinolfi L, Sarnelli G, Loffredo F, Efficie E, et al Oesophageal acid exposure and altered neurocardiac function in patients with GERD and idiopathic cardiac dysrhythmias. Aliment Pharmacol Ther 2006; 24 (2):361-370.

24. Maruyama T, Fukata M, Akashi K. Association of atrial fibrillation and gastroesophageal reflux disease: Natural and therapeutic linkage of the two common diseases. J Arrhythm 2019; 35 (1):43-51.

25. Souza RF. Reflux esophagitis and its role in the pathogenesis of Barrett's metaplasia. J Gastroenterol 2017; 52 (7):767-776.

26. Souza RF, Huo X, Mittal V, Schuler CM, Carmack SW, Zhang HY, et al. Gastroesophageal reflux might cause esophagitis through a cytokinemediated mechanism rather than caustic acid injury. Gastroenterology 2009; 137 (5):1776-1784.

27. Dunbar KB, Agoston AT, Odze RD, Huo X, Pham TH, Cipher DJ, et al. Association of Acute Gastroesophageal Reflux Disease With Esophageal Histologic Changes. JAMA 2016; 315 (19):2104-2112.

28. Kahrilas PJ. Turning the Pathogenesis of Acute Peptic Esophagitis Inside Out. JAMA 2016; 315 (19):2077-2078.

29. Hu YF, Chen YJ, Lin YJ, Chen SA. Inflammation and the pathogenesis of atrial fibrillation. Nat Rev Cardiol 2015; 12 (4):230-243.

30. Lindhardsen J, Ahlehoff O, Gislason GH, Madsen OR, Olesen JB, Svendsen $\mathrm{JH}$, et al. Risk of atrial fibrillation and stroke in rheumatoid arthritis: Danish nationwide cohort study. BMJ 2012; 344:e1257.

31. Rhee TM, Lee JH, Choi EK, Han KD, Lee H, Park CS, et al. Increased Risk of Atrial Fibrillation and Thromboembolism in Patients with Severe Psoriasis: a Nationwide Population-based Study. Sci Rep 2017; 7 (1):9973.

32. Efe TH, Cimen T, Ertem AG, Coskun Y, Bilgin M, Sahan HF, et al. Atrial Electromechanical Properties in Inflammatory Bowel Disease. Echocardiography 2016; 33 (9):1309-1316.

33. Packer M. Epicardial Adipose Tissue May Mediate Deleterious Effects of Obesity and Inflammation on the Myocardium. J Am Coll Cardiol 2018; 71 (20):2360-2372.

34. Nagashima K, Okumura Y, Watanabe I, Nakai T, Ohkubo K, Kofune M, et al. Does location of epicardial adipose tissue correspond to endocardial high dominant frequency or complex fractionated atrial electrogram sites 
during atrial fibrillation? Circ Arrhythm Electrophysiol 2012; 5 (4):676683.

35. Bos D, Vernooij MW, Shahzad R, Kavousi M, Hofman A, van Walsum T, et al. Epicardial Fat Volume and the Risk of Atrial Fibrillation in the General Population Free of Cardiovascular Disease. JACC Cardiovasc Imaging 2017; 10 (11):1405-1407.

36. Schieber M, Chandel NS. ROS function in redox signaling and oxidative stress. Curr Biol 2014; 24 (10):R453-462.

37. Feagins LA, Zhang HY, Zhang X, Hormi-Carver K, Thomas T, Terada LS, et al. Mechanisms of oxidant production in esophageal squamous cell and Barrett's cell lines. Am J Physiol Gastrointest Liver Physiol 2008; 294 (2):G411-417.

38. Huo X, Agoston AT, Dunbar KB, Cipher DJ, Zhang X, Yu C, et al. Hypoxiainducible factor-2alpha plays a role in mediating oesophagitis in GORD. Gut 2017; 66 (9):1542-1554.

39. Van Wagoner DR. Oxidative stress and inflammation in atrial fibrillation: role in pathogenesis and potential as a therapeutic target. J Cardiovasc Pharmacol 2008; 52 (4):306-313.

40. Cai H, Li Z, Goette A, Mera F, Honeycutt C, Feterik K, et al. Downregulation of endocardial nitric oxide synthase expression and nitric oxide production in atrial fibrillation: potential mechanisms for atrial thrombosis and stroke. Circulation 2002; 106 (22):2854-2858.

41. Mihm MJ, Yu F, Carnes CA, Reiser PJ, McCarthy PM, Van Wagoner DR, et al. Impaired myofibrillar energetics and oxidative injury during human atrial fibrillation. Circulation 2001; 104 (2):174-180.

42. Antonopoulos AS, Goliopoulou A, Oikonomou E, Tsalamandris S, Papamikroulis GA, Lazaros G, et al. Redox State in Atrial Fibrillation
Pathogenesis and Relevant Therapeutic Approaches. Curr Med Chem 2019; 26 (5):765-779.

43. Carnes CA, Janssen PM, Ruehr ML, Nakayama H, Nakayama T, Haase H, et al. Atrial glutathione content, calcium current, and contractility. J Biol Chem 2007; 282 (38):28063-28073.

44. Ahlehoff O, Gislason GH, Charlot M, Jorgensen CH, Lindhardsen J, Olesen $\mathrm{JB}$, et al. Psoriasis is associated with clinically significant cardiovascular risk: a Danish nationwide cohort study. J Intern Med 2011; 270 (2):147157.

45. Wei-Syun H, Lin CL. CHA2DS2-VASc score for prediction of ischemic stroke in patients with systemic lupus erythematosus without atrial fibrillation. Lupus 2018; 27 (8):1240-1246.

46. Zha AM, Di Napoli M, Behrouz R. Prevention of Stroke in Rheumatoid Arthritis. Curr Neurol Neurosci Rep 2015; 15 (12):77.

47. Turagam MK, Velagapudi P. Gut To Heart: Acid Reflux Disease In Atrial Fibrillation And The Role Of Proton Pump Inhibitor. J Atr Fibrillation 2014; 7 (3):1031. 
medRxiv preprint doi: https://doi.org/10.1101/2020.08.07.20169482; this version posted August 11, 2020. The copyright holder for this preprint (which was not certified by peer review) is the author/funder, who has granted medRxiv a license to display the preprint in perpetuity.

All rights reserved. No reuse allowed without permission.

Jiang et al, Aug 07, 2020

Table 1. Demographics and baseline characteristics of patients admitted for atrial fibrillation with and without reflux esophagitis.

\begin{tabular}{lccc}
\hline & AF with RE & AF without RE & $P$ value \\
& 5,396 & 5,396 & \\
& & & \\
\hline Age, year & $73.6 \pm 0.4$ & $74.2 \pm 0.4$ & 0.32 \\
ECl score & $3.3 \pm 0.2$ & $3.0 \pm 0.2$ & 0.47 \\
Female & $3,160(58.5 \%)$ & $3,080(57.1 \%)$ & 0.95 \\
Caucasian & $4,310(79.9 \%)$ & $4,305(79.8 \%)$ & 0.80 \\
Large hospital & $3,050(56.5 \%)$ & $3,000(55.6 \%)$ & 0.83 \\
Urban teaching hospital & $2,232(41.4 \%)$ & $2,306(42.7 \%)$ & 0.76 \\
Medicare insured & $4,132(76.6 \%)$ & $4,191(77.7 \%)$ & 0.89 \\
Routine disposition & $3,656(67.9 \%)$ & $3,596(66.6 \%)$ & \\
\hline
\end{tabular}

N, Weighted number; AF, Atrial fibrillation; RE, Reflux esophagitis; ECl, Elixhauser Comorbidity Index. 
medRxiv preprint doi: https://doi.org/10.1101/2020.08.07.20169482; this version posted August 11, 2020. The copyright holder for this preprint (which was not certified by peer review) is the author/funder, who has granted medRxiv a license to display the preprint in perpetuity. All rights reserved. No reuse allowed without permission.

Jiang et al, Aug 07, 2020

Table 2. Comparison of selected comorbidities of patients admitted for atrial fibrillation with and without reflux esophagitis.

AF with RE

$\mathrm{N}$

5,396
$\mathrm{CHA}_{2} \mathrm{DS}_{2}$-VASc score

0

1

$>=2$

Tobacco use disorder

Dyslipidemia

Obesity

Congestive heart failure

Hypertension

Diabetes mellitus

History of stroke, TIA, or thromboembolism

Thromboembolic disease

Acute myocardial infarction

Prior myocardial infarction

Prior $\mathrm{PCl}$

Prior CABG

Valvular disease

Prior valvular surgery

Cardiogenic shock

Cardiac arrest

Chronic liver disease

Chronic pulmonary disease

Renal failure

Catheter ablation

Open surgical ablation

Electric cardioversion
AF without RE

5,396
0.67

$139(2.6 \%)$
$407(7.5 \%)$
$4,850(89.9 \%)$

$1,359(25.2 \%)$

$2,743(50.8 \%)$

744 (13.8\%)

$169(3.1 \%)$

$3,839(71.1 \%)$

$1,428(26.5 \%)$

$560(10.4 \%)$

$40(0.7 \%)$

$20(0.4 \%)$

432 (8.0\%)

417 (7.7\%)

387 (7.2\%)

184 (3.4\%)

134 (2.5\%)

$5(0.1 \%)$

15 (0.3\%)

144 (2.7\%)

$1,543(28.6 \%)$

694 (12.9\%)

$119(2.2 \%)$

$20(0.4 \%)$

446 (8.3\%)
$129(2.4 \%)$

357 (6.6\%)

4,910 (91.0\%)

$1,364(25.3 \%)$

0.96

2,386 (44.2\%)

0.002

694 (12.9\%)

0.53

159 (2.9\%)

0.80

3,819 (70.8\%)

0.85

$1,468(27.2 \%)$

0.69

526 (9.7\%)

0.62

$15(0.3 \%)$

0.13

$45(0.8 \%)$

0.18

392(7.3\%)

0.52

$422(7.8 \%)$

0.94

382 (7.1\%)

0.93

159 (2.9\%)

0.55

188 (3.5\%)

0.17

20 (0.4\%)

0.18

$10(0.2 \%)$

0.65

60 (1.1\%)

0.0067

1,146 (21.2\%)

0.0001

600 (11.1\%)

0.21

188 (3.5\%)

0.08

$10(0.2 \%)$

0.41

471 (8.7\%)

0.69 
medRxiv preprint doi: https://doi.org/10.1101/2020.08.07.20169482; this version posted August 11, 2020. The copyright holder for this preprint (which was not certified by peer review) is the author/funder, who has granted medRxiv a license to display the preprint in perpetuity.

All rights reserved. No reuse allowed without permission.

Jiang et al, Aug 07, 2020

Table 3. Multivariate regression analysis of inpatient outcomes for patients admitted for atrial fibrillation with and without reflux esophagitis

\begin{tabular}{|c|c|c|c|c|c|c|}
\hline & AF with RE & $\begin{array}{c}\mathrm{AF} \\
\text { without } \\
\mathrm{RE}\end{array}$ & $\begin{array}{l}\text { Unadjusted } \\
\text { odds ratio } \\
\text { or } \\
\text { coefficient } \\
(95 \% \mathrm{Cl})\end{array}$ & $P$ value & $\begin{array}{l}\text { Adjusted } \\
\text { odds ratio } \\
\text { or } \\
\text { coefficient* } \\
(95 \% \mathrm{Cl})\end{array}$ & $P$ value \\
\hline Acute stroke & 25 & 10 & 2.51 & 0.015 & 2.34 & 0.028 \\
\hline and TIA & (0.46\%) & (0.19\%) & $(1.2,5.24)$ & & $(1.1,4.99)$ & \\
\hline Acute heart & 109 & 129 & 0.84 & 0.194 & 0.79 & 0.076 \\
\hline failure & (2.02\%) & (2.39\%) & $(0.65,1.09)$ & & $(0.61,1.02)$ & \\
\hline Hospital & 64 & 50 & 1.3 & 0.161 & 1.35 & 0.123 \\
\hline mortality & (1.19\%) & (0.93\%) & $(0.9,1.89)$ & & $(0.92,1.99)$ & \\
\hline \multirow[t]{2}{*}{ LOS, day } & 4.05 & 3.48 & 0.56 & & 0.54 & \\
\hline & $(0.11)$ & $(0.10)$ & $(0.28,0.85)$ & $<0.0001$ & $(0.27,0.82)$ & 0.0001 \\
\hline \multicolumn{7}{|l|}{ Total } \\
\hline hospitalization & 36,095 & 32,114 & 3,980 & 0.0240 & 3,890 & 0.0250 \\
\hline charges, & $(1,409)$ & $(1,122)$ & $(518,7,443)$ & & $(483,7,297)$ & \\
\hline
\end{tabular}

Data are presented as mean (standard errors) or absolute numbers (\%)

AF, Atrial fibrillation; RE, Reflux esophagitis; Cl, Confidence interval; TIA, Transient ischemic attack; LOS, Length of stay.

*Adjusted for age, sex, race, primary insurance payer, hospital type, hospital bed size, income quartile, $\mathrm{CHA}_{2} \mathrm{DS}_{2}$-VASc score, Elixhauser Comorbidity Index score, dyslipidemia, chronic liver disease, and chronic pulmonary disease. 